\title{
Energy balance: a crucial issue for exercise and sports medicine
}

\author{
Steven N Blair, ${ }^{1}$ Gregory A Hand, ${ }^{2}$ James 0 Hill ${ }^{3}$
}

${ }^{1}$ Department of Exercise Science, Department of Epidemiology and Biostatistics, Arnold School of Public Health, University of South Carolina, South Carolina, USA; ${ }^{2}$ School of Public Health, West Virginia University; ${ }^{3}$ Anschutz Health and Wellness Center, University of Colorado

Correspondence to Professor Steven N Blair, Department of Exercise Science, Department of Epidemiology and Biostatistics, Arnold School of Public Health, University of South Carolina, SC 29208, USA; sblair@mailbox.sc.edu
The recently published issue of British Journal of Sports Medicine (http://bjsm. bmj.com/content/49/4.toc) includes articles on several important topics in exercise science and sports medicine. We are grateful to the many leading clinicians and scientists who have made these contributions. This editorial will address another relevant topic that requires focused attention-energy balance.
BACKGROUND

Non-communicable chronic diseases (NCDs), such as cardiovascular disease, cancer, obesity and type 2 diabetes, are clearly the leading public health problems facing the world in the 21st century. ${ }^{1}$ The causes of NCDs are predominately unhealthful lifestyles such as physical inactivity, poor diets, smoking, unhealthful sleep habits and not managing stress effectively. ${ }^{1}$ In recent years, obesity rates have increased in most countries, and this problem receives enormous attention, in both the popular media and scientific press. The fundamental cause of increasing rates of obesity is too many people being in a positive energy balance on too many days; but the problem is very complex. ${ }^{2}$ From a simple perspective, 
energy balance is the ratio of energy intake and energy expenditure, and if more calories are consumed than are expended, a person will be in positive energy balance. This excessive energy will be stored in the body, mostly as body fat. Of course maintaining energy balance is a much more complex issue than this simple statement, with numerous environmental, social and physiological factors having a role. Extensive reviews of the energy balance concept have been published in recent years. ${ }^{34}$

\section{ENERGY FLUX - A RECENT CONCEPT}

Energy flux refers to the rate of energy flow through a system. Recently this concept has been applied to the rate of energy flow in the human body. ${ }^{5}$ Mayer et $a l^{6}$ postulated that individuals with a high rate of energy flow through the body (ie, high intake matched by high expenditure) were better able to maintain energy balance than those with a low rate of energy expenditure. It should be noted that at a very sedentary level, the participants had energy intake similar to that of the highly active individuals. Blundell ${ }^{7}$ referred to a low energy flux as the unregulated zone where energy intake and expenditure were not well matched and where the likelihood of positive energy balance was high. He referred to a moderate and high energy flux as the regulated zone where energy intake was well matched to level of energy expenditure (eg, better appetite control). Energy balance at a high energy flux is seen typically in those with high levels of physical activity. A low energy flux may be an unstable situation that is resolved by increasing body mass, which in turn increases energy expenditure and energy flux. This last point reinforces the 'drive' to maintain a relatively high energy intake which requires either equivalent energy expenditure or energy storage. To maintain a high energy flux in the face of a sedentary lifestyle, there is no option other than significant energy storage.

The fact that food restriction has not proven to be an effective means of longterm weight control is consistent with the flux hypothesis. People need to be in the regulated zone to be better able to match caloric intake to caloric expenditure over long time periods. In addition, drastic caloric restriction by sedentary individuals in an effort to lose body weight creates a number of health concerns including cachexia, reduction in bone density, impaired immune function and fatigue. Finally, the reduced resting metabolic rate resulting from excessive caloric restriction reduces the likelihood of sustained weight management at a lower body weight over time.

\section{IMBALANCE IN ENERGY BALANCE INFORMATION}

Energy balance is an important public health issue, and we have focused on this issue for the past few years. We are obtaining detailed information on energy intake, energy expenditure, energy storage and other variables in a cohort of young adults. ${ }^{8}$ The overall purpose is to provide better information on how changes in both sides of the energy balance equation are related to changes in body weight and composition.

There is enormous confusion about the relation of energy intake and energy expenditure to obesity. A Google search on 1 January 2015 produced the following results:

- Physical inactivity and obesity966000 hits;

- Diet and obesity-70300000 hits.

Of course Google hits are primarily from public media, and it also is important to see if a similar imbalance is present in the scientific literature, so we searched for these same terms on PubMed. Here are the results:

- Physical inactivity and obesity-2176 manuscripts;

- Diet and obesity-44 584 manuscripts. Both of these data searches show that much more attention is focused on diet and obesity than on physical inactivity and obesity. We need more research that focused on energy balance-not just a single component of energy balance. As indicated above, we are currently conducting research that will provide extensive data on the contributions of the two sides of the energy balance equation to weight change.

\section{DEALING WITH UNBALANCED INFORMATION ABOUT ENERGY BALANCE}

We clearly need a much more balanced approach to discussing energy balance and energy flux. We have created a not-forprofit organisation, the Global Energy Balance Network that focuses attention on making sound information about both sides of the energy balance equation readily available to the public, clinicians and scientists. The mission of the organisation can be found at http://www.gebn.org. We invite you to view the website and send us suggestions and information.
Competing interests The Global Energy Balance Network has received support from private philanthropy, the University of Colorado, the University of South Carolina, the University of Copenhagen, including an unrestricted education gift from The CocaCola Company. GEBN believes that finding workable solutions to correcting energy imbalance will be achieved faster by working with all sectors of society. GEBN seeks support to continue our efforts from both the public and private sectors.

Provenance and peer review Not commissioned; externally peer reviewed.

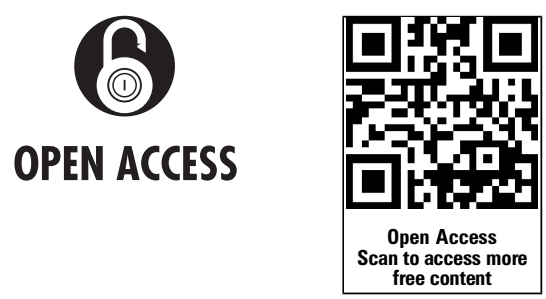

Open Access This is an Open Access article distributed in accordance with the Creative Commons Attribution Non Commercial (CC BY-NC 4.0) license, which permits others to distribute, remix, adapt, build upon this work non-commercially, and license their derivative works on different terms, provided the original work is properly cited and the use is noncommercial. See: http://creativecommons.org/licenses/ by-nc/4.0/

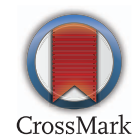

To cite Blair SN, Hand GA, Hill JO. Br J Sports Med 2015;49:970-971.

Accepted 14 February 2015

Published Online First 13 March 2015

Br J Sports Med 2015;49:970-971.

doi:10.1136/bjsports-2015-094592

\section{REFERENCES}

1 Murray CJL, Lopez AD. Measuring the global burden of disease. N Engl J Med 2013;369: 448-57.

2 Shook RP, Blair SN, Duperly J, et al. What is causing the worldwide rise in body weight? US Endocrinol 2014; 10:44-52.

3 Hill JO, Wyatt HR, Peters JC. The importance of energy balance. US Endocrinol 2013;9:27-31.

4 Hill JO, Wyatt HR, Peters JC. Energy balance and obesity. Circulation 2012;126:126-32.

5 Hand GA, Blair SN. Energy flux and its role in obesity and metabolic disease. US Endocrinol 2014; 10:59-64.

6 Mayer J, Roy P, Mitra KP. Relation between caloric intake, body weight, and physical work: studies in an industrial male population in West Bengal. Am J Clin Nutr 1956;4:169-75.

7 Blundell JE. Physical activity and appetite control: can we close the energy gap? Nutr Bull 2011;36:356-66.

8 Hand GA, Shook RP, Paluch AE, et al. The energy balance study: the design and baseline results for a longitudinal study of energy balance. Res $Q$ Exerc Sport 2013;84:275-86. 